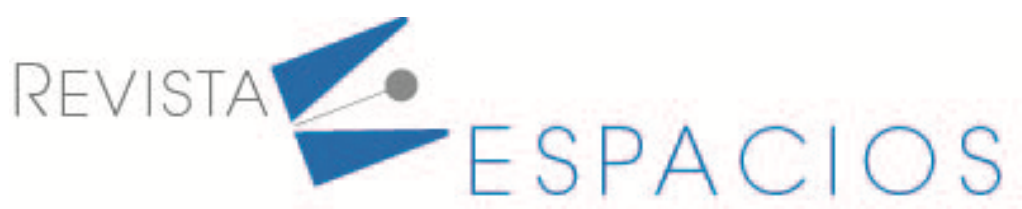

\title{
A new flexible benchmarking monitoring system: a case study for the civil construction sector in Brazil
}

\section{Un nuevo sistema flexible de monitoreo de evaluación comparativa: un estudio de caso para el sector de la construcción civil en Brasil}

\author{
ALBERTIN, Marcos R. ${ }^{1}$ \\ PONTES, Heráclito L.J. ${ }^{2}$ \\ ARAGÃO JUNIOR, Dmontier P. ${ }^{3}$ \\ PRATA, Bruno A. ${ }^{4}$ \\ BALTAZAR, Marcos C.P. ${ }^{5}$
}

\begin{abstract}
This paper aims at presenting a new flexible benchmarking model in civil construction. It describes an explanatory case study whereby data are collected through an internet benchmarking system with multi-criteria performance. This case study was based on the Production Arrangements Monitoring and Benchmarking System (SIMAP), the authors describe a flexible benchmarking model considering 46 criteria classified into 7 subsystems. The proposed benchmarking system can be used by companies from other countries with proper adaptations.

Keywords: multi-criteria performance, civil construction supply chain, decision analysis.
\end{abstract}

\begin{abstract}
Resumen
Este artículo tiene como objetivo presentar un modelo nuevo de benchmarking flexible en la construcción civil. Describe un estudio de caso explicativo en el que se recopilan los datos por el internet a través de un sistema de benchmarking con un rendimiento de criterios múltiples, basado en el Sistema de Monitoreo y Benchmarking de Arreglos de Producción (SIMAP) considerando 46 criterios clasificados en 7 subsistemas. Este procedimiento puede ser utilizado por empresas de otros países con las adaptaciones adecuadas.

Palabras clave: desempeño de criterios múltiples, cadena de suministro de construcción civil, análisis de decisiones
\end{abstract}

\section{Introduction}

In recent decades, globalization has highlighted the inability of companies to aggregate all the skills necessary for their survival. As a result, corporate interrelationships are not only seen as trade relations but opportunities

\footnotetext{
${ }^{1}$ Associate Professor. Dept. of Industrial Engineering, Federal Univ. of Ceará. Fortaleza, Ceará, Brazil, 60440-554. Contact: albertin@ot.ufc.br.

${ }^{2}$ Associate Professor. Dept. of Industrial Engineering, Federal Univ. of Ceará. Fortaleza, Ceará, Brazil, 60440-554. Contact: hjaguaribe@ufc.br

${ }^{3}$ Assistant Professor. Federal Univ. of Ceará. Russas, Ceará, Brazil, 62900-000. Contact: dmontier.aragao@ufc.br.

${ }^{4}$ Associate Professor. Dept. of Industrial Engineering, Federal Univ. of Ceará. Fortaleza, Ceará, Brazil, 60440-554. Contact: baprata@ufc.br.

${ }^{5}$ EBTT Professor. Logistics Coordination, Federal Institute of Alagoas. Maceió, Alagoas, Brazil, 57084-649. Contact: marcos.charles@ifal.edu.br.
} 
to add value and complementarities. Thus, there is a rapid growth in relationships as collaborative networks and supply chains; clusters, virtual companies, joint ventures, consortiums, alliances, among others, referred to in this work as productive arrangements (PAs).

Johnson (2008) notes that benchmarking surveys have been made with a focus on intra-relationships, instead of business interrelationships and business networks. Simatupang (2004) states that there is a positive correlation between collaboration and performance ratios, and encourages collaborative efforts among the participants in a supply chain to improve its operating results.

Civil construction is an important sector in the Brazilian economy, which is growing fast in recent years. With this growth, competitiveness in the sector has played a key role for companies in the market. Therefore, national companies have sought to promote continuous improvement in their operations based on modern and flexible managerial techniques.

Concerning the application of benchmarking and performance measurement in civil construction, several papers have been reported in the literature. The proposition of Key Performance Indicators (KPIs) and benchmarking models are presented by Beatham et al. (2004), Chan \& Chan, (2004), Fang et al. (2004), Ramirez et al. (2004), Lee et al. (2005), Park et al. (2005), Costa et al. (2006), Cox et al. (2006), El-Mashaleh et al. (2007), Yeung et al. (2007), Yeung et al. (2008), Yeung et al. (2009a), Yeung et al. (2009b), Ahuja et al. (2010), Yeung et al. (2013), Abbasian-Hosseini et al. (2014) and Vogl \& Abdel-Wahab (2015). However, studies which approach the proposition of flexible benchmarking models in the civil construction sector are scarce in the literature.

The main objective of this paper is to propose a new flexible benchmarking monitoring system to evaluate the performance of civil construction companies. Furthermore, we present a case study with Brazilian companies. The contributions of the paper are threefold: (1) the application of an innovative web computer system for the implementation of a flexible benchmarking model in the civil construction sector, (2) the application of a multicriteria benchmarking model based on a flexible system available on the internet, and (3) the presentation of a case study based on the Brazilian reality.

The remainder of this paper is organized as follows. In section two, we present the proposed flexible benchmarking model. In section three, we describe a case study with real-world data. Finally, in the last section, we provide some concluding remarks and suggestions for future research.

\section{Proposed flexible benchmarking model: SIMAP}

The SIMAP (Production Arrangements Monitoring and Benchmarking System - in Portuguese) has as its purpose monitoring companies, links (processes) as well as productive chains of the main PAs in Brazil (Albertin et al., 2015; Albertin et al., 2016). Through agile and clear communication, all the stakeholders in the analyzed PAs perform collaborative actions (in the form of benchmarking), making information available about strategic performance, managerial technologies, processes, and products, guiding actions and efforts for systemic competitiveness.

The SIMAP is an interactive benchmarking tool created to help companies, developing agencies, and policymakers identify challenges and opportunities for improving their performance. Through a significant sample of collected data, the system allows for a more productive dialogue among government and companies based on information updated dynamically, avoiding inefficient and unfocused actions. To sum up, a company can compare itself with the average of the registered companies, in the state and local where they act. It can also identify benchmark companies, which are a reference of efficiency (performance) and effectiveness (results) to other companies that belong to the same link or have a similar process (Albertin et al., 2014). 
Implementation and monitoring of a benchmarking system is a complex process because a group of companies is observed and not just an isolated company. A system like SIMAP is a part of a dynamic and complex market, requiring continuous monitoring that identifies bottlenecks and technological constraints cooperatively and collaboratively, considering performance indicators previously defined.

SIMAP is an innovative internet benchmarking and monitoring system that provides an online benchmarking analysis that addresses the need for performance assessment tools. With this innovative tool any firm, in the PAs previously mapped can participate and view the individual performance analysis results in real-time. The information of each company is confidential, and aggregated data are presented only as statistical parameters for comparison.

The inclusion of data in SIMAP occurs with the indication of the location, which can be local, regional, or national, as represented in the axis "territory" in Figure 1. This figure illustrates some possible comparisons in SIMAP. The axis "activities" provides the benchmarking by activity (process) of a supply chain compared to other links of the same or different production chains. It is possible, for example, for a machining company to compare itself with the average performance of companies from other states and countries, and with its direct competitors in the same supply chain (territory) or the same state. It is possible to draw a value chain, a supply chain, cluster, or other types of productive arrangements (PA), and make restricted or unrestricted access comparisons.

Figure 1

Possible comparisons on SIMAP

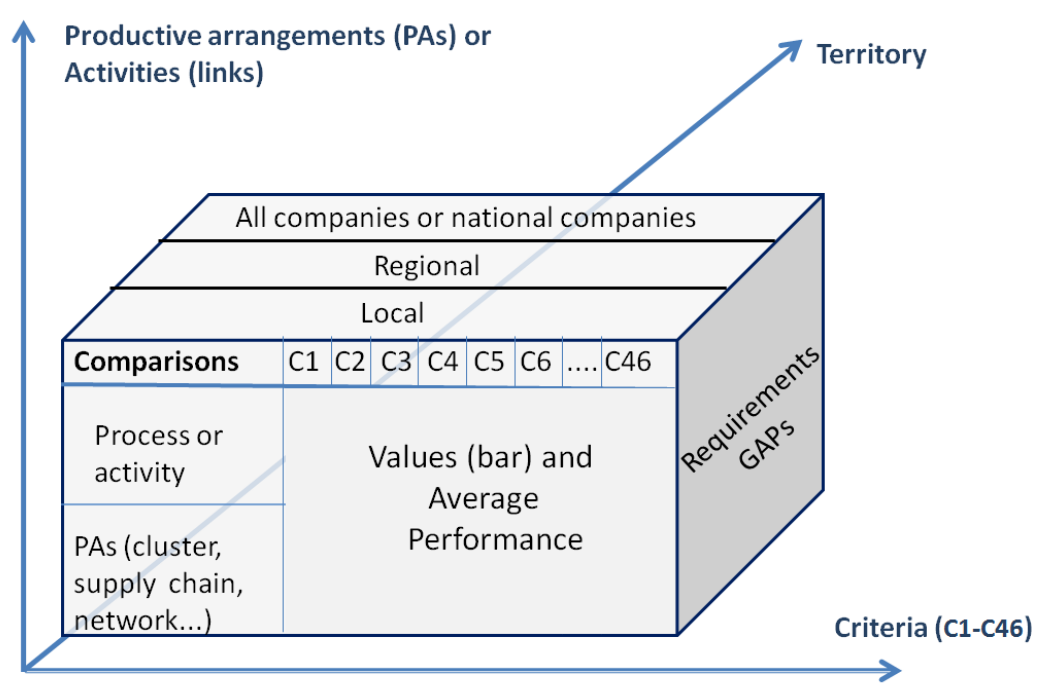

Source: compiled by authors

The 46 criteria (C1, C2, ..., C46) shown in Figure 2 were grouped by similarity on seven subsystems: Integrated Management System (GP01), Production Management (GP02), Products Management (GP03), Strategic Management (GP04), Logistic Management (GP05), Human Resources Management (GP06), and Financial Management (GP07). 
Figure 2

Application of SIMAP. Source: authors

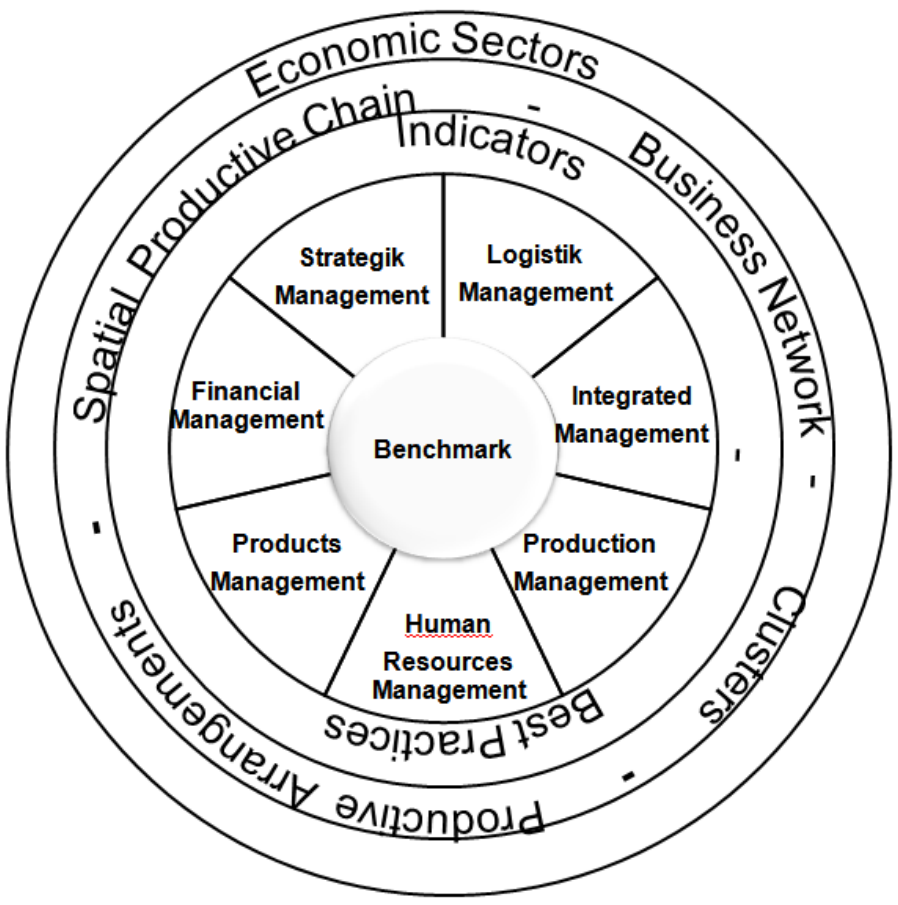

Source: compiled by authors

Each criterion has a growing performance metric adapted from a Likert scale of five levels $(0,25,50,75,100)$, featuring categorized qualitative data. These criteria represent best practices as technologies of product, processes, and management associated with indicators and methods. There is the possibility of "not applicable" when the same cannot be implemented in a particular company.

The criteria and performance levels derive from the requirements established in the Malcolm Bridge Award, as well as in the Toyota Production System, ISO / TS 16949, and ISO 9001. Each subsystem was set based on interviews with companies and professionals to identify the most important tools. A minimal or desirable performance (requirement) to delivery to a focal company was identified for each PA (Figure 3). The performance requirements (dotted line) were established by the focal firm in the supply chain or by experts and were considered dynamic and market pre-requisites desired by potential suppliers. The data was collected by interviews, technical visits, and mainly by internet. As a method to analyze the collected dates we are using: (a) bars graphics and means, and (b) individual and collective visual gaps analysis. It is observed in Figure 3 the performance of a company (bar chart) and the mean comparison of performance in the GP01 to GP07 subsystems (Albertin et al., 2014). The differences between the performance (bars) and industry requirements (dotted line) are called bottlenecks or gaps. As shown SIMAP allows viewing "online and on time" gaps for any company registered for free. Gaps are considered technical barriers to supply the local production chain. 
Figure 3

Individual performance (bars) and the average performance (line)

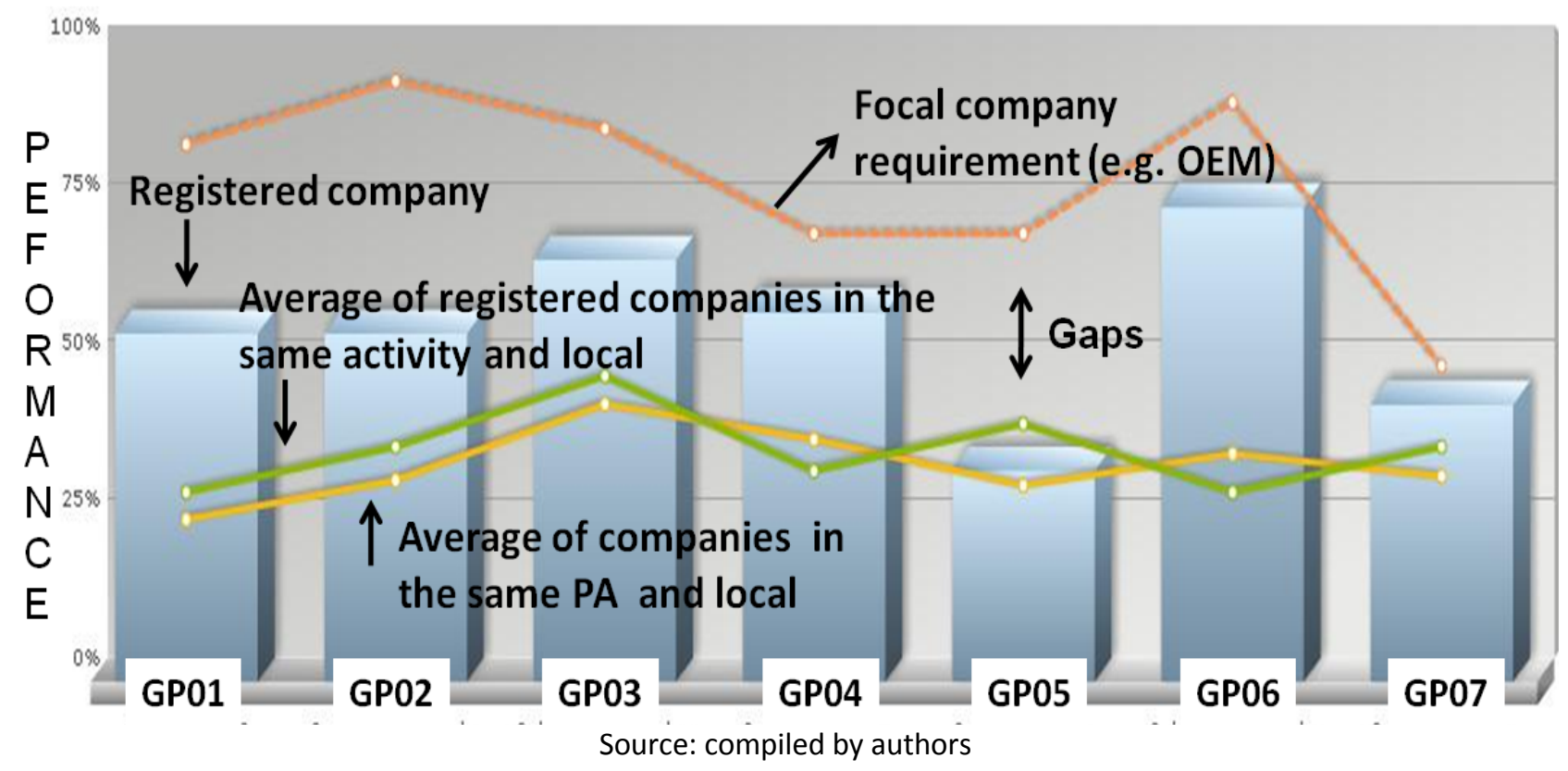

The system architecture of SIMAP, which was adapted from the work of Johnson et al. (2010), is represented in Figure 4. We use a three-tier application consisting of a web system, a database, and statistical tools.

Figure 4

SIMAP System Architecture

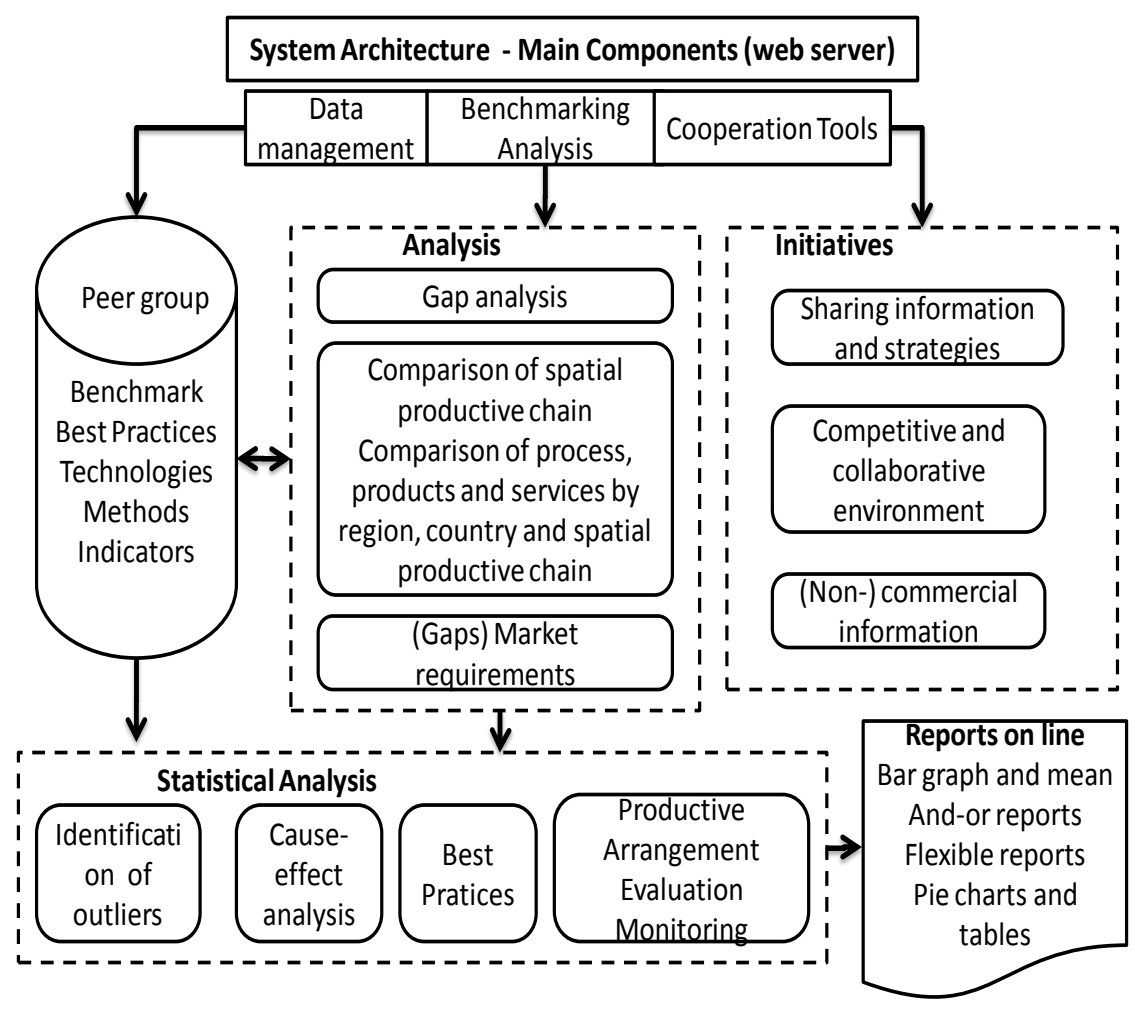

Source: adapted from Johnson et. al., (2010) 
The web system is based on open-source software that allows adjustments on demand. This makes the system more attractive since different PAs and others customizations can be implemented into the system. This web system makes it possible to provide a flexible survey form directly to the companies. Among all the information collected, could be highlighted the levels of adoption of technologies, best practices, methods, and indicators. With this kind of knowledge, it is possible to verify the market requirements, the gap of the companies of this market requirements, besides a lot of other benchmarking information.

The information collected in the web system is stored in a database, which is a structured collection of records stored in a computer allowing further consultations for retrieval of information. The database is responsible for storing and querying data stored using it for a relational structure, where tables have links to each other.

The storage of the information in the database as it was modeled ensures that the system is resilient to events such as the creation or extinction of a PA, a link, a subsystem, or even a criterion. This flexibility preserves the information already captured, and the system administrator, or even the companies themselves, must update the records already made in the system, thus preventing the need for collecting any information again.

About the statistical tools, the third tier of SIMAP, the one can see some online statistical analysis. However, SIMAP administrators could use different tools for offline statistical analysis.

The online statistical analysis indicates the need for improvements in the 46 performance criteria. The SIMAP collects, processes and reports information in real-time to any company in any place, PAs, or links. The greater the number of registered companies the greater the possibilities of comparison and the more representative the database will be. The database can be continually updated by the companies, enabling individual and collective tracking of the PAs. The main online graphics enabled in the SIMAP are (i) bar and sequential reports; (ii) Data Envelopment Analysis (DEA); (iii) Flexible report on the administrative area; and (iv) Flexible reports open to companies.

In turn, the offline analysis uses the data exported from the database, this data is imported could be used in software like "Project R", this tool is an open-source initiative and have contributions from hundreds of researchers. With tools like that, several analyses could be made: identification of outliers, cause-effect analyses, best practices identification, different scatter plots, among others. This analysis improves the benchmarking with very useful information.

The freedom to access SIMAP through the internet allows the partner firm to perform several comparisons and simulations, as: (i) positioning the company relative to the average performance of competitors; (ii) performance of a firm against the average of all companies in the same link in the same chain; (iii) comparative acting against other links, supply chains or location; (iv) performance of a firm against the average of all listed companies; (v) performance of the benchmarking company against the average of all companies in the same link in the same chain; (vi) performance by business size (small medium and large business) and (vii) the development gaps for a given technology.

\section{Case study}

To demonstrate the application of the proposed benchmarking model, we used data from a real case, which consists of a group of 82 civil construction companies in Brazil with operations in the areas presented in Table 1. 
Table 1

Activities of the companies understudy

\begin{tabular}{|c|c|c|c|c|c|}
\hline Company Activity (Link) & $\begin{array}{l}\text { Number of } \\
\text { companies }\end{array}$ & $\%$ & Company Activity (Link) & $\begin{array}{l}\text { Number of } \\
\text { companies }\end{array}$ & $\%$ \\
\hline Mortar and whitewash & 3 & $3.57 \%$ & Sawmill & 2 & $2.38 \%$ \\
\hline Sand and gravel & 3 & $3.57 \%$ & Retail trade of building materials & 1 & $1.19 \%$ \\
\hline Cement & 2 & $2.38 \%$ & Projects & 6 & $7.14 \%$ \\
\hline $\begin{array}{c}\text { Merchant bars and metal } \\
\text { structures }\end{array}$ & 8 & $9.52 \%$ & Machine and equipment rental & 4 & $4.76 \%$ \\
\hline Electric materials & 3 & $3.57 \%$ & Outsourced labor & 3 & $3.57 \%$ \\
\hline Glassware & 1 & $1.19 \%$ & Housing & 1 & $1.19 \%$ \\
\hline Red ceramic & 25 & $29.76 \%$ & $\begin{array}{c}\text { Machine and equipment } \\
\text { manufactures }\end{array}$ & 2 & $2.38 \%$ \\
\hline White ceramic & 1 & $1.19 \%$ & Builders and developers & 24 & $28.57 \%$ \\
\hline Tiles & 6 & $7.14 \%$ & $\begin{array}{c}\text { Wholesale stores of building } \\
\text { materials }\end{array}$ & 4 & $4.76 \%$ \\
\hline Pipes and connections & 4 & $4.76 \%$ & Plastic materials & 1 & $1.19 \%$ \\
\hline $\begin{array}{c}\text { Sanitary equipment and } \\
\text { metal segment }\end{array}$ & 6 & $7.14 \%$ & Wall and floor covering & 2 & $2.38 \%$ \\
\hline Inks and varnishes & 5 & $5.95 \%$ & Others & 13 & $15.48 \%$ \\
\hline
\end{tabular}

Source: compiled by authors

The observed companies were obtained from the SIMAP database via the internet, allowing for flexible and lowcost data gathering. The results for the calculated performance indicators for each criterion in each subsystem are presented in Table 2.

The average performance of firms by size is shown in Figure 5. It can be observed that the average performance of large companies is around the range of $50-75 \%$, the performance of medium-sized companies is close to $50 \%$, while the performance of small businesses oscillates around $25 \%$. The range of $25 \%$ indicates an effort towards the formalization and standardization of processes. The overall performance of all companies is represented by the 3 rd line (overall average) in the range between 25 and $50 \%$. 
Table 2

Company performance for each criterion in each subsystem

\begin{tabular}{|c|c|c|c|c|c|c|c|c|c|c|c|}
\hline \multirow{2}{*}{ 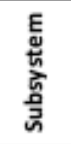 } & \multirow[b]{2}{*}{ Criteria } & \multicolumn{4}{|c|}{ (\%) } & \multirow{2}{*}{ 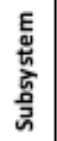 } & \multirow[b]{2}{*}{ criteria } & \multicolumn{4}{|c|}{$(\%)$} \\
\hline & & small & medium & all & large & & & small & medium & all & large \\
\hline \multirow{6}{*}{ 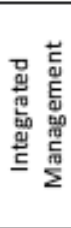 } & 1. ISO 9001 & 24,6 & 57,9 & 37,4 & 100,0 & \multirow{7}{*}{ 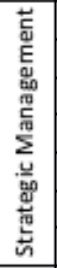 } & 22. Strategic planning & 20,0 & 59,2 & 32,1 & 66,7 \\
\hline & 2. ISO 14001 & 8,3 & 29,0 & 15,6 & 45,8 & & 23. Production strategies & 27,2 & 65,8 & 39,8 & 79,2 \\
\hline & $3.5 \mathrm{~S}$ & 19,2 & 48,6 & 28,9 & 66,7 & & 24. Leadership style & 32,1 & 65,8 & 42,4 & 70,8 \\
\hline & 4. SA 8000 & 8,9 & 22,2 & 12,7 & 20,8 & & 25. Benchmarking use & 29,2 & 47,4 & 35,3 & 58,3 \\
\hline & 5. OSHAS 18000 & 10,2 & 29,4 & 17,1 & 50,0 & & 26. Customers focus & 35,4 & 61,8 & 45,0 & 87,5 \\
\hline & Average & 14,2 & 37,4 & 22,3 & 56,7 & & 27. Use of indicators & 33,8 & 65,8 & 45,0 & 91,7 \\
\hline \multirow{11}{*}{ 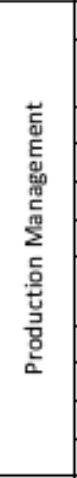 } & 6. Setup time & 17,7 & 18,3 & 18,3 & 25,0 & & \begin{tabular}{|l|} 
Average \\
\end{tabular} & 29,6 & 61,0 & 39,9 & 75,7 \\
\hline & $\begin{array}{l}\text { 7.Production Planning and } \\
\text { control }\end{array}$ & 50,4 & 60,5 & 54,6 & 75,0 & \multirow{13}{*}{ 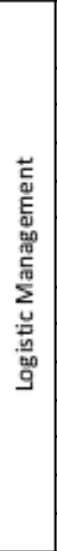 } & 28.Stock control & 25,4 & 59,7 & 36,3 & 75,0 \\
\hline & 8. Capability studies & 22,0 & 29,3 & 48,5 & 45,8 & & 29. Stock rotativity & 11,1 & 36,5 & 17,4 & 25,0 \\
\hline & 9. Quality costs & 13,0 & 38,2 & 20,7 & 45,0 & & 30.Logistics services & 13,6 & 30,8 & 17,6 & 18,8 \\
\hline & 10. Process control & 26,7 & 39,5 & 30,9 & 45,8 & & 31. Handling & 28,9 & 50,0 & 34,7 & 50,0 \\
\hline & 11. Part per million & 29,7 & 56,9 & 38,7 & 70,8 & & 32. Unitization & 41,0 & 59,2 & 44,9 & 37,5 \\
\hline & \begin{tabular}{|l|} 
12. Total preventive \\
maintenance \\
\end{tabular} & 28,6 & 30,0 & 29,4 & 41,7 & & 33.Material flow & 13,0 & 34,6 & 18,3 & 25,0 \\
\hline & 13. Just in Time & 29,2 & 46,1 & 34,7 & 54,2 & & 34. Information flow & 19,2 & 34,2 & 25,3 & 58,3 \\
\hline & 14. Suppliers development & 19,4 & 30,6 & 24,1 & 50,0 & & 35.Financial flow & 35,6 & 43,4 & 36,9 & 29,2 \\
\hline & 15. Average age of equipment & 33,1 & 43,4 & 38,4 & 75,0 & & 36. Commerce transaction & 29,1 & 47,1 & 33,1 & 30,0 \\
\hline & Average & 27,0 & 41,2 & 31,9 & 52,8 & & 37. Warehouse control & 12,0 & 38,5 & 19,8 & 50,0 \\
\hline \multirow{7}{*}{ 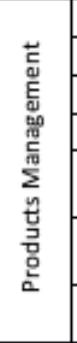 } & 16. Use of technical norms & 40,2 & 75,0 & 51,9 & 87,5 & & 38.Transportation system & 21,1 & 47,9 & 28,3 & 50,0 \\
\hline & 17. CAD/CAE/CAM & 19,6 & 34,2 & 26,3 & 58,3 & & 39. Supply chain relationship & 12,8 & 40,4 & 19,0 & 18,8 \\
\hline & 18. Multifunctional groups & 18,1 & 40,3 & 26,6 & 62,5 & & Average & 21,9 & 43,5 & 27,6 & 39,0 \\
\hline & 19. Time to market & 20,4 & 35,9 & 25,3 & 45,0 & \multirow{4}{*}{ 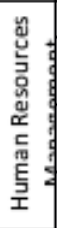 } & 40.Trainings program & 27,5 & 51,3 & 35,9 & 70,8 \\
\hline & $\begin{array}{l}\text { 20.Methodology for } \\
\text { development of new products }\end{array}$ & 23,1 & 41,7 & 30,5 & 66,7 & & 41. Competence program & 25,8 & 46,1 & 33,5 & 70,8 \\
\hline & $\begin{array}{l}\text { 21. Suppliers and customers } \\
\text { partnerships }\end{array}$ & 42,5 & 73,7 & 52,1 & 75,0 & & 42. Collaborative program & 14,6 & 47,4 & 25,0 & 58,3 \\
\hline & Average & 27,3 & 50,1 & 35,5 & 65,8 & & Average & 22,6 & 48,3 & 31,5 & 66,7 \\
\hline \multirow{5}{*}{ 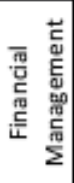 } & 43. ERP & 17,8 & 47,4 & 28,9 & 79,2 & \multirow{5}{*}{ ' } & - & - & - & - & - \\
\hline & \begin{tabular}{|l|} 
44. Direct cost \\
\end{tabular} & 22,5 & 50,0 & 32,1 & 70,8 & & - & - & - & - & - \\
\hline & 45. ABC method & 16,5 & 44,7 & 26,5 & 66,7 & & - & - & - & - & - \\
\hline & 46.Analysis of investment & 17,4 & 42,1 & 26,5 & 66,7 & & - & - & - & - & - \\
\hline & Average & 18,5 & 46,1 & 28,5 & 70,8 & & - & - & - & - & - \\
\hline
\end{tabular}

Source: compiled by authors

Figure 5

Company performance for each in each subsystem

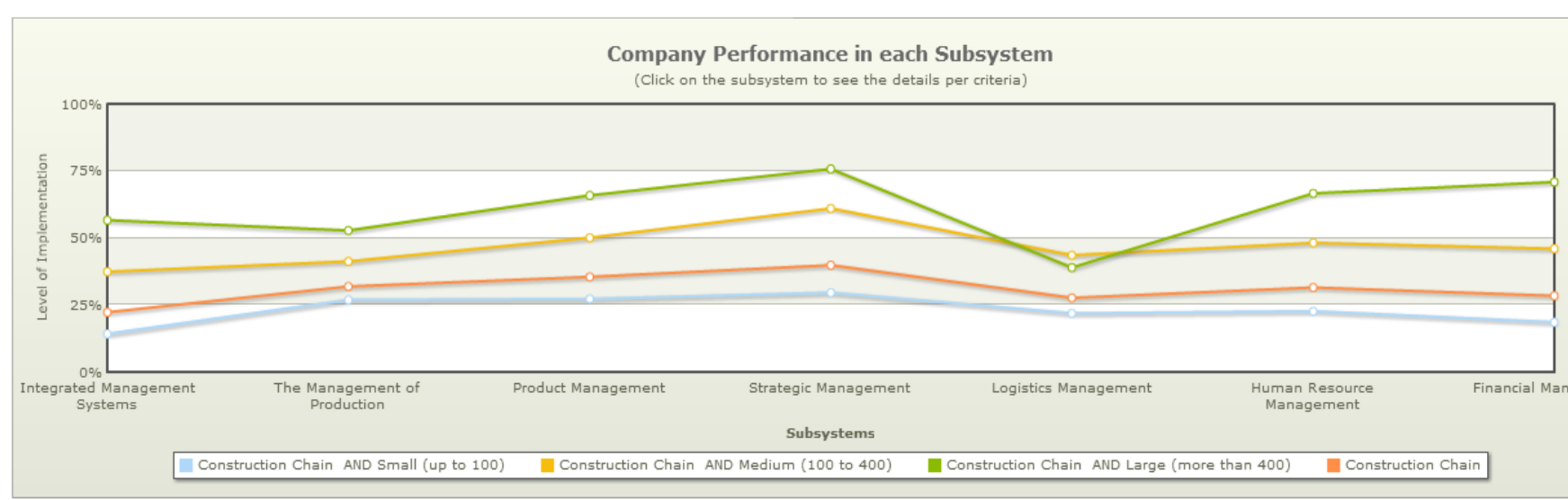

Source: compiled by authors 
The results obtained for subsystem 1 (Integrated Management System, criteria 1 to 5) point out a lack of formal procedures for small-size companies. We can be observed that some of the standard requirements are legal provisions (safety and health standards) and are required by the market. The certification (100\%) to international standards ISO 9001 (C1) is not implemented yet in most small and mid-size companies. Better performance in these criteria is strongly recommended for a general improvement of the analyzed sector.

Criteria 8 (capability studies) presents an average performance of $22 \%$, meaning that the analyzed companies have, in general, instabilities in their processes and difficulties in controlling them. The processes of small businesses are unstable and they generate excessive costs with control, rework and scrap. Several companies may not reach the prices demanded by potential clients because of the excess control of the products and the high rejection rates.

Criteria 16 (use of technical norms) presents an average performance greater than $50 \%$, indicating that the analyzed companies know the main technical norms about their products and services. Several types of products, services, and qualifications are specified by national or international norms, and the ignorance of or the nonfulfillment of these specifications does not qualify a given company for the supply chains.

In the Strategic Management subsystem, the average values for indicators 22 to 27 indicate that a centralized style in management does not create a good environment for innovation and continuous improvement of processes. In general terms, the analyzed companies adopted a centralized management model, which is often an inhibitor to the best managerial practices.

Regarding criteria 40,41, and 42, the human resource departments of the analyzed companies are, in general terms, in a stage of incipient implementation. Thus, they do not promote programs with discretionary participating features and competence assessment systems. Finally, about Financial Management, one can observe that the greater part of the analyzed companies uses informal tools for their financial management.

\section{Conclusions}

The benchmarking method described in this paper is promising for evaluating civil construction companies, considering several fields of activities and multiple criteria. The approach proposed in this paper is a useful tool to support decision-making in civil construction, aimed at identifying the best managerial practices in the sector.

Regarding the presented case study, we can be observed that larger size companies presented a better performance than the small and medium-sized companies, except for the Logistics Management subsystem, in which medium-sized companies have performed somewhat better. Beyond this particular area, larger size companies presented a significant superiority in all the subsystems, expressed by the average values for the performance indicators evaluated. Thus, the development of mechanisms for the transference of good management practices is of great importance for the improvement of the sector as a whole. The average performance of small businesses indicates that they are in transition to standardization for Quality and Process Control.

As a research limitation, we can observe that for monitoring and trending analysis more data and time is needed. This three-year application shows that it takes a long time to build a database that can be meaningful for benchmarking and monitoring purposes management. It also requires management maturity, performance systems, and procedures to invite companies to collect and input data online.

As a further development of the work presented in this paper, the authors are currently working on an extension of the database, considering companies from other regions of Brazil, as well as expanding the benchmarking system with supplementary financial indicators (Lima et al., 2017). Furthermore, the methodology adopted here 
could be extended to other types of companies, such as logistics and transportation firms (Chin et al., 2005; Siaudzionis Filho et al., 2018).

\section{Acknowledgments}

The authors wish to thank the Federal Institute of Alagoas (IFAL) for funding this work.

\section{References}

Albertin, M. R., Pontes, H. L. J., Frazzon, E. M., \& Frota, E. R. (2014). Industrial performance assessment through the application of a benchmarking and monitoring system. In: 4th International Conference on Dynamics in Logistics.

Albertin, M. R., Pontes, H. L. J., Frazzon, E. M., \& Frota, E. R. (2016). Industrial Performance Assessment through the Application of a Benchmarking and Monitoring System. In Dynamics in Logistics (pp. 643-653). Springer, Cham.

Albertin, M.R., Pontes, H. L. J., Frota, E. R., \& Assunção, M. B. (2015) Flexible benchmarking: a new reference model. Benchmark. Int. J., v. 22 (5), 920-944.

Abbasian-Hosseini, S. A., Hsiang, S. M., Leming, M. L., \& Liu, M. (2014). From Social Network to Data Envelopment Analysis: Identifying Benchmarks at the Site Management Level. J. Constr. Eng. Manage., 140(8), 1-10.

Ahuja, V., Yang, J., \& Shankar, R. (2010). Benchmarking Framework to Measure Extent of ICT Adoption for Building Project Management. J. Constr. Eng. Manage., 136(5), 538-545.

Beatham, S., Anumba, C., Thorpe, T., \& Hedges, I. (2004). KPIs: A critical appraisal of their use in construction. Benchmark. Int. J., 11(1), 93-117.

Chan, A. P. C., \& Chan, A. P. L. (2004). Key performance indicators for measuring construction success. Benchmark. Int. J., 11(2), 203-221.

Chin, S. Y., Pontes, H. L. J., \& Porto, A. L. V. (2005) Retrieving process analysis in a parts distribution center: a case study of manual trolley fleet substitution. In Proceedings of the Winter Simulation Conference 2005.

Costa, D. B., Formoso, C. T., Kagioglou, M., Alarcón, L. F., \& Caldas, C. H. (2006). Benchmarking initiatives in the construction industry: Lessons learned and improvement opportunities. J. Manage. Eng.,22(4), 158-167.

Cox, R. F., Issa, R. R. A., \& Ahrens, D. (2003). Management's perception of key performance indicators for construction. J. Constr. Eng. Manage., 129(2), 142-151.

El-Mashaleh, M. S., Minchin, R. E., \& O’Brien, W. J. (2007). Management of construction firm performance using benchmarking. J. Manage. Eng., 23(1), 10-17.

Fang, D. P., Huang, X. Y., \& Hinze, J. (2004) Benchmarking Studies on Construction Safety Management in China. J. Constr. Eng. Manage., 130(3), 424-432.

Johnson, A., Chen, W. C., \& Mcginnis, L. F. (2010) Large-scale Internet benchmarking: Technology and application in warehousing operations. Computers in Industry [S.I.], v. 61, n. 3, p. 280-286.

Johnson, W. H. (2008) Roles, resources and benefits of intermediate organizations supporting triple helix collaborative R\&D: The case of Precarn. Technovation, 28, 495-505. 
Lee, S. H., Thomas, S. R., \& Tucker, R. L. (2005) Web-Based Benchmarking System for the Construction Industry. J. Constr. Eng. Manage., 131(7), 790-798.

Lima, R. S., Albertin, M. R., Loos, M. J., \& Vital, T. (2017). Análise de compras por pregão eletrônico na modalidade licitatória em uma empresa do setor de distribuição energética. Espacios (Caracas) (38), 10 - 22.

Park, H. S., Thomas, S.R., \& Tucker, R.L. (2005) Benchmarking of Construction Productivity. J. Constr. Eng. Manage., 131(7), 772-778.

Ramirez, R. R, Alarcón, L. F. C., \& Knights, P. (2004). Benchmarking system for evaluating management practices in the construction industry. J. Manage. Eng., 20(3), 110-117.

Siaudzionis Filho, F. A. B., Pontes, H. L. J., Albertin, M. R., de Lima, R. L. M., \& de Castro Moraes, T. (2018). Application of visual management panel on an airplane assembly station. International journal of productivity and performance management (67), $1045-1062$.

Simatupang, T. M. (2004) Benchmarking supply chain collaboration An empirical study. Benchmarking: an International Journal, 11 (5), $484-503$.

Vogl, B., \& Abdel-Wahab, M. (2015) Measuring the Construction Industry's Productivity Performance: Critique of International Productivity Comparisons at Industry Level. J. Constr. Eng. Manage., 141(4), 1-10.

Yeung, J. F. Y., Chan, A. P. C., \& Chan, D. W. M. (2008). Establishing quantitative indicators for measuring the partnering performance of construction projects in Hong Kong. Constr. Manage. Econ., 26(3), 277-301.

Yeung, J. F. Y., Chan, A. P. C., \& Chan, D. W. M. (2009a). A computerized model for measuring and benchmarking the partnering performance of construction projects. Autom. Constr., 18(8), 1099-1113.

Yeung, J. F. Y., Chan, A. P. C., \& Chan, D. W. M. (2009b). Developing a performance index for relationship-based construction projects in Australia: Delphi study. J. Manage. Eng., 25(2), 59-68.

Yeung, J. F. Y., Chan, A. P. C., Chan, D. W. M., \& Li, L. K. (2007). Development of a partnering performance index (PPI) for construction projects in Hong Kong: A Delphi study. Constr. Manage. Econ., 25(12), 1219-1237.

Yeung, J. F. Y., Chan, A. P. C., Chan, D. W. M., Chiang, Y. H., \& Yan, H. (2013) Developing a Benchmarking Model for Construction Projects in Hong Kong. J. Constr. Eng. Manage., 139(6), 705-716.

Esta obra está bajo una Licencia Creative Commons Attribución-NoCommercial 4.0 International

(cc) BY-NC 